\title{
ANÁLISIS DE LOS TRABAJOS GEOLÓGICOS DE WILLIAM M. GABB SOBRE COSTA RICA, A LA LUZ DEL PARADIGMA GEOLÓGICO DEL SIGLO XIX
}

\author{
Percy Denyer ${ }^{1} \&$ Gerardo J. Soto ${ }^{2}$
}

1) Escuela Centroamericana de Geología, Universidad de Costa Rica, Apdo. 2-14--2060, Costa Rica. Correo electrónico<:pdenyer@ cariari.ucr.ac.cr 2) Oficina de Sismología y Vulcanología, Instituto Costarricense de Electricidad (Dirección actual: Kõtokuji-dai 5-1-16-24, Kagoshima-shi 891-0103, Japón).

\author{
(Recibido 20/4/1999; Aceptado 10/9/1999)
}

\begin{abstract}
We have the aim to rescue the geologic work of William M. Gabb, into the historic framework of the last century. The reason Gabb came to Costa Rica was related to speculations about the presence of huge mineral deposits in Costa Rica, which woke up the cupidity of the Keith brothers.

The geologic work of W. M. Gabb in Costa Rica was a big step, because he was the first geologist to make geological maps and who apported regional conclusions. Unfortunately, nobody continued his work, his geologic map was never published until now (we areincluding a reproduction of his map). His geographic map of Talamanca was published by Petermann in the last century. He died only four years after his departuring from Costa Rica, and this could have been the main reason, that all of his reports were not properly published. His work was not only restricted to Talamanca: he also visited several volcanoes, the Candelaria range and the Nicoya peninsula.

He nominated around 50 new species of moluska. Stratigraphically, he understood the sucessions very well, because he wrote about the Miocene sedimentary rocks, plutonic rocks forming the nuclei of the Talamanca range, dikes of volcanites,"antillites" (as he named the fossil corals), and alluvial plains. We believe, Gabb was much more an explorer-like geologist, than a man who enjoy to be into the four walls of a laboratory. This quality made him able to caarry out the geologic exploration of California, Santo Domingo and Costa Rica. When we compare his work through the paradigm of his epoch, Gabb results an exceptional geologist, who made minor mistakes. His errors are related to the geologic concepts of the last century, an epoch were the structural geology was not developed, and the paradigmatic concept of the Western Indies avoid a better approach to the modern models. The wrong idea with respect of the existence of metamorphic rocks in Costa Rica was because of a translation mistake of the term "shale" to Spanish as "esquisto".
\end{abstract}

RESUMEN: Pretendemos, con este trabajo, rescatar la labor de William M. Gabb como geólogo dentro del marco histórico de la época. La venida de Gabb está relacionada con especulaciones sobre la existencia de grandes yacimientos minerales en Costa Rica, lo cual despertó la codicia de los hermanos Keith.

Para la geología de Costa Rica, los trabajos de Gabb aportaron mucho, y de hecho fue el primer geólogo que vino a hacer mapas y quien da conclusiones regionales. Desgraciadamente no hubo quién continuara su labor, tanto así, que el mapa geológico de Talamanca nunca se publicó, y no es sino hasta ahora que se hace una reproducción de éste. Otra contribución muy importante fue su mapa geográfico de Talamanca, que fue publicado como parte de los aportes geográficos de Petermann, de finales del siglo pasado.

Su pronta muerte, sólo cuatro años después de dejar Costa Rica, tuvo mucho que ver en que parte de sus trabajos nunca fueran debidamente publicados. El aporte de Gabb estriba no sólo en sus conclusiones y su mapa geológico de Talamanca, sino que visita varios volcanes y escribe sobre algunas de sus giras a los cerros de Candelaria y la Península de Nicoya.

Dentro de la Paleontología, nomina unas 50 especies nuevas de moluscos. Estratigráficamente, Gabb dominaba muy bien las sucesiones, por lo que describe las unidades de rocas en Talamanca, que incluyen: rocas sedimentarias miocenas, intrusivos que conforman el núcleo de la cordillera de Talamanca, vulcanitas en forma de diques, "antillitas" (o corales fósiles) y el relleno aluvial.

Consideramos que Gabb era mucho más un geólogo-explorador y aventurero que una persona que gustara del trabajo de laboratorio, lo que le permitió realizar exploraciones regionales en California, Santo Domingo y Costa Rica. Al comparar sus trabajos a la luz de los paradigmas de la época, Gabb destaca como un geólogo excepcional, incurriendo en errores mínimos, propios de un momento en que la geología estructural estaba apenas en sus inicios, y donde el paradigma sobre las Indias Occidentales justamente impedían un mayor acercamiento a modelos mucho más acorde con nuestro esquema de realidad geológica que se maneja actualmente. Aparentes errores de apreciación respecto a la existencia de rocas metamórficas quedan esclarecidos, pues resulta ser un problema de traducción que todavía era utilizado hace menos de cuarenta años "shale" por "esquisto". 


\section{INTRODUCCIÓN}

Algunos de los investigadores naturalistas que vinieron a Costa Rica en el siglo XIX desarrollaron trabajos de índole geológica, sin embargo los dos primeros geólogos sensu stricto que llegaron e hicieron trabajos geológicos de detalle y amplitud, fueron Karl von Seebach en 1864 y William M. Gabb en 1873 (Dengo, 1988). Seebach se dedicó al estudio de los volcanes (Seebach, 1865a y b; 1892), mientras que Gabb, fue el primer naturalista con estudios formales en Geología, que realmente llevó a cabo investigaciones geológicas integrales y regionales. $\mathrm{R}$. Hoffstetter escribió en la introducción del apartado de Costa Rica en el Léxico Estratigráfico de América Central (Hoffstetter et al., 1960): " ...el verdadero pionero es Gabb quien, después de recorrer gran parte del territorio, proporcionó las bases esenciales de la geología del país".

Existen dos libros (traducidos al español) que recogen algunos de los escritos geológicos y étnicos de Gabb, y que que son muy similares en su primera parte. El primero fue introducido por Henri Pittier (Gabb, 1895), e incluye nueve capítulos, sobre la geología y geografía, más un apéndice sobre las colecciones de Gabb de batracios y reptiles. El segundo libro tiene una introducción de Luis Ferrero, donde se incluye la primera parte titulada "El Espacio", que es casi idéntica al libro introducido por Pittier y una segunda sección titulada "Los Hombres" (Ferrero, 1978), donde se recopilan algunos de los escritos de Gabb, más relacionadas a las costumbres de los indígenas.

La historia total que envolvió a Gabb en Costa Rica es apasionante, y a pesar de haber sido contratado con fines aplicados muy específicos, derivó en suculentas investigaciones científicas, y en la producción del primer mapa geológico detallado de una gran parte de Costa Rica. Curiosamente este mapa permaneció inédito, como ya ha sido señalado por González Flores (1976, p. 193) y Draper \& Dengo (1990, p. 3).

Sobre las razones por las cuales Gabb llegó a Costa Rica, Dengo (1988) escribió: "En la parte sur del istmo, en Costa Rica, desde tiempo de la Colonia existía la leyenda de fabulosas minas de oro, nunca encontradas, en la cordillera de
Talamanca y sus estribaciones hacia el Caribe." Por esto, los Keith (Minor y Henry Meiggs) tratan de contratar a Von Seebach y W. M. Gabb. Finalmente solo Gabb viene, y por diversos motivos políticos su contratación se traspasa al gobierno de la República.

El propósito de este trabajo es rescatar parte de su labor como geólogo, y analizar el trabajo que desarrolló, a la luz de los paradigmas geológicos del entonces. Presentamos una reproducción del mapa geológico de la Talamanca, y una copia del mapa geográfico de parte de Costa Rica. El primer mapa nunca fue publicado y el segundo aparece en una publicación de Petermann (1877). Los antecedentes históricos que rodearon la venida de Gabb, las intenciones específicas sobre su traída y la contribución de Gabb a la cartografía del país, se detallarán en otra publicación que se envió a la revista Anuario de Estudios Centroamericanos.

\section{ANTECEDENTES HISTÓRICOS SOBRE LA LLEGADA DE WILLIAM M. GABB A COSTA RICA}

La llegada de Gabb a Costa Rica estuvo relacionada con una serie de hechos históricos que involucraron no sólo a Costa Rica, sino a América Latina entera en su relación al potencial imperialista de los Estados Unidos. Por lo tanto, se hará un esbozo general para poder ubicar la venida de Gabb en un contexto histórico, para lo que hemos utilizado las obras de Salazar (1996), Stewart (1991) y Anónimo (1997).

En los albores de los años setentas del siglo pasado, Tomás Guardia se propuso llevar un ferrocarril desde el Valle Central hasta el Caribe, y es donde entra a figurar en la historia de Costa Rica, la familia Keith: Henry Meiggs, hermano de la madre de Minor Keith y sus sobrinos Minor Keith y Henry Meiggs Keith.

Henry Meiggs había ejecutado una enorme estafa en California por lo que huyó a Chile en 1855 y hacia 1860 inició varias obras ferrocarrileras con éxito, por lo que ganó mucho dinero y fama. En 1868 llegó a Perú y para 1871 había alcanzado a firmar siete contratos para la 
construcción de ferrocarriles en ese país. En 1871, un representante del Presidente Guardia, firmó en Lima el contrato de construcción con Henry Meiggs. Henry y el General Guardia jamás se conocieron en persona y, ni por un sólo día, estuvo en Costa Rica, pero encargó a su sobrino Henry Meiggs Keith la tarea. El contrato quedó, de hecho, traspasado en el mismo momento de firmarse. Henry M. Keith le escribió a su hermano Minor, que se encontraba en Estados Unidos, para que le ayudara en el trabajo, por lo que se trasladó a Costa Rica en agosto de 1871 y Minor se le unió a principios de setiembre de 1871 en Puntarenas.

Una vez que ambos hermanos se radicaron en Costa Rica, es seguro que fueron notificados de las serias expectativas en minerales metálicos y no metálicos -entiéndase oro y carbón- que tenía la casi inexplorada Talamanca. Recordemos que a finales de la década de los sesentas del siglo pasado, las expectativas mineras en Costa Rica, sobre todo con respecto al oro y al carbón, eran muy altas. Ya en 1835 habían siete minas, que producían cerca de dos y medio millones de pesos y empleaban a más de cuatrocientas personas (Fuentealba, 1977; Ulloa, 1979; Villalta, 1986). Y quizás la mayores esperanzas se cifraban en zonas que aún se encontraban bastante inexploradas, y de las cuales existían antecedentes míticos de yacimientos, como es el caso de la Talamanca, de donde habían leyendas de grandes yacimientos: La Estrella y el Tisingal, desde denuncios de los primeros conquistadores como Juan Vásquez de Coronado en 1645 (Albúm de Figueroa, p. 140, Archivos Nacionales de Costa Rica (ANCR)).

Minor Keith tenía intereses mercantiles en varios países: minas de hierro en Honduras, minas de oro de Abangares, la Panama Corporation Ltd., la Premier Gold Mining Company en la Colombia Británica y poseía una enorme colección de varios miles de piezas indígenas, calificada por el New York Tribune como "la más valiosa colección del mundo de piezas de oro de culturas antiguas" (Salazar, 1996, p. 343-344).

Esta fiebre de oro, compartida por su hermano Henry, es indudablemente el incentivo que impulsó a Henry, junto con J.P. O’Sullivan, la compañía alemana Hübbe und Greytzell, Guillermo Nanne y Eusebio Figueroa, a hacer una osada propuesta al gobierno de la República, el 8 de abril de 1872 (ANCR, \#1139, Sección Administrativa, Serie 3a, Tomo 77, titulado "Solicitud"), para promover la colonización del territorio comprendido entre el río Banano en el Atlántico, hasta el río General en el Pacífico, es decir unos $13000 \mathrm{~km}^{2}$ del actual territorio de Costa Rica -lo que viene a ser un $25 \%$-, y abarcaría todo el sur de la provincia de Limón, casi toda la provincia de Puntarenas, y los extremos oriental de Cartago y sureste de San José, además de un grueso territorio del actual Panamá, pues la frontera con la Nueva Granada o Colombia, estaba en ese tiempo bastante más al este que hoy.

Entre las variadas concesiones que solicitaron al gobierno en esta propuesta, se pueden mencionar: derechos de fundar una o más colonias de extranjeros y concederles naturalización automática a los colonos que residan por más de dos años; dar principio a estudios topográficos por medio de una comisión científica; derechos de la propiedad de las vetas metálicas y cualesquiera otras como carbón o mármol, así como las maderas y cualesquiera otros productos de los terrenos, sin quedar sujeta en cuanto a las minas a los términos que las leyes del ramo fijan para su laboreo; exención de impuestos durante veinte años para los colonos; libertad sin prohibición gubernamental de montar cualquier industria; no pagar derechos de importación o exportación; al llegar a dos mil habitantes, la colonia elegiría sus propios regentes y reglamentos, aunque a los veinte años después se convertiría en otra provincia de la República. Henry Keith y sus socios presentaron el proyecto al Presidente Guardia, y éste lo remitió en su forma original al Congreso. El cual rechazó el proyecto y lo devolvió al Poder Ejecutivo. Los Keith deben haber albergado aún esperanzas de obtener grandes concesiones en el área de Talamanca, pues sólo así se explica que aún habiendo recibido una negativa del Congreso, Henry M. Keith intentaron contratar a William Gabb.

Para prospectar los minerales que ansiaban los Keith, necesitaban entonces, de un equipo de geólogos, para lo cual contactaron a Karl 
von Seebach, que ya conocía Costa Rica, y a William M. Gabb. En octubre de 1872 Henry le propuso a Gabb hacer estudios de Geología, Topografía e Historia Natural en Talamanca, o cualquier otra parte de Costa Rica que se le designe, con el propósito de hacer mapas exactos, investigar la posibilidad de hacer asentamientos de gente blanca, así como recabar datos climáticos. Von Seebach sería el jefe de la misión, pero que en caso de que éste no acepte, le proponía que tomara a cargo también la jefatura y se le asignaría un sueldo de trescientos pesos (\$300) por mes, y sobre todo una prohibición expresa de publicar cualquier dato o informe científico sin su aprobación (ANCR, \# 378, Sección Administrativa, Serie 3a, titulada "Comunicación" (copia)). Aunque no está documentado, aparentemente Seebach no acepta la proposición y finalmente es sólo Gabb quien se encargó de la exploración de la Talamanca. Quien firma el contrato con Gabb es Henry Meiggs Keith, y no su hermano Minor, como erróneamente lo consignan González Flores (1976) y Dengo (1988), aunque para efectos prácticos, ambos hermanos eran una unidad, y fue finalmente Minor el que dejó una profunda cicatriz en la historia de Costa Rica, pues Henry M. Keith enfermó de paludismo y murió en 1875.

Gabb llegó a Puntarenas el 4 de febrero de 1873 a hacerse cargo de la misión. El contrato que habían firmado Keith y Gabb, pasó al Gobierno de Costa Rica, sin ser muy claro y no haber prácticamente nada escrito sobre el asunto, incluso se puede presumir que existió algún acuerdo secreto con el presidente Tomás Guardia. Escueto y directo, el mismo Gabb (1875) explicó este traspaso de la siguiente forma: "Yo estuve primero contratado por una compañía de las personas de vanguardia en Costa Rica, nativos y extranjeros, pero después de todo el gobierno tomó a su cargo el proyecto y asumió la responsabilidad del trabajo". Sin embargo, el mismo Gabb destacó, que siempre recibía instrucciones de Keith (ver Carta-prólogo, Gabb, 1895).

Las ideas de los Keith para hacer exploraciones geológicas en Talamanca, son clarificadas por el mismo Gabb (1875), de la siguiente manera: "El objetivo principal de la exploración fue el redescubrimiento de algunas minas, cuya existencia es reportada por la tradición, de las cuales se han dicho historias fabulosas". Queda claro entonces, el objetivo que tenían los Keith, para traer a Gabb, que dicho sea de paso, era un geólogo con inclinación a la Paleontología y la Geología Regional, pero con alguna experiencia minera, como lo atestiguan dos publicaciones de la década de 1860-1870 (Cuadro 1), cuando trabajaba con el Servicio Geológico de los Estados Unidos, en California.

\section{¿QUIÉN FUE WILLIAM MORE GABB?}

Gabb (1839-1878) (Fig. 1) fue hijo de Joseph, comerciante, y Christina. Nació en Filadelfia el 20 de enero de 1839. Asistió a la escuela pública, y su educación secundaria la recibió en la renombrada "Central High School" de Filadelfia,

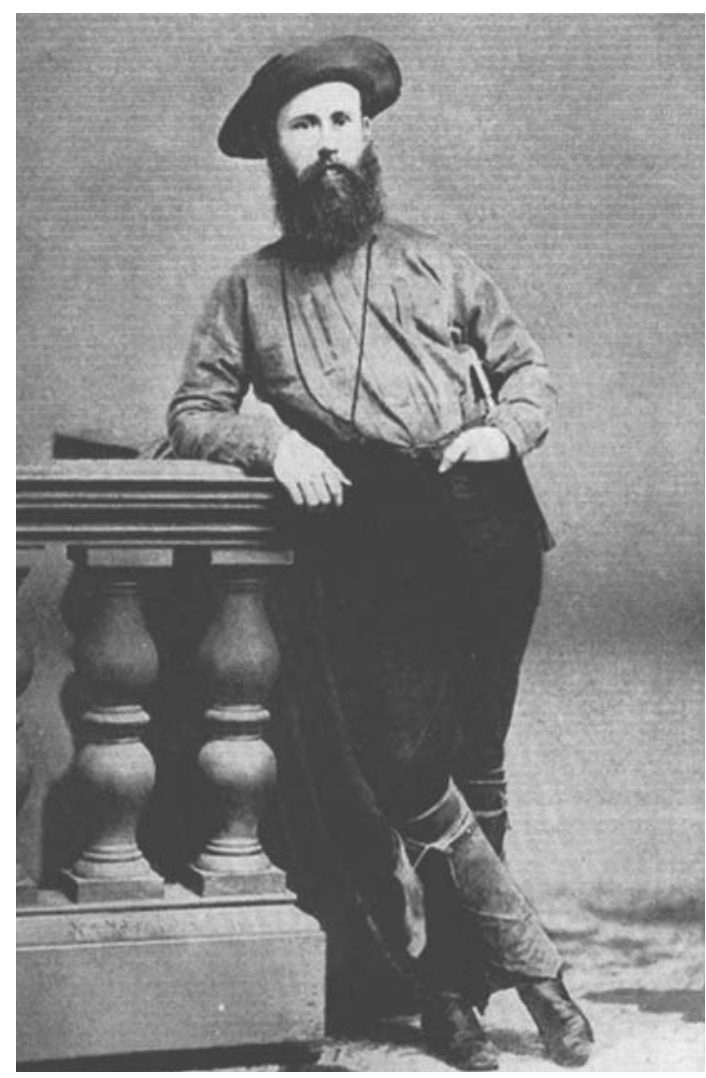

Fig. 1: Fotografía de William M. Gabb de 1863, tomada de Schuchert (1935). 
donde se graduó con honores. Mostró siempre mucho interés por las ciencias naturales, la malacología y la mineralogía, e incluso era un frecuente visitante del Museo de la Academia Natural de Ciencias. En febrero de 1857 recibió el grado de Arts Bachelor, y unos años más tarde, la maestría. Su biógrafo, Dall (1909), del cual extractamos la mayor parte de su biografía, expresa su extrañeza de que Gabb haya podido seguir su inclinación por la ciencia, por carecer de recursos financieros.

En un período no definido entre 1857 y 1860, sirvió como asistente del Profesor James Hall, el más connotado geólogo de la época. El 31 de enero de 1860 fue electo miembro de la Academia de Ciencias Naturales de Filadelfia y en 1862 miembro y curador de la Academia de Ciencias de California. Entre 1862 y 1867 trabajó para el Servicio Geológico del Estado de California, en las montañas del valle de California, aunque también estuvo en el desierto de Mojave, Fort Tejon, Oregon, Sierra Nevada, la sierra de la Costa, la Montaña Blanca y Baja California. Dedicó gran parte de 1865 a trabajar con los fósiles, y gracias a sus cualidades artísticas, él mismo preparaba sus propios dibujos.

En 1868 rompió su conexión con el Servicio Geológico y en 1869 reinició sus investigaciones, pero ahora como jefe de exploración topográfica y geológica en República Dominicana, contratado directamente por el gobierno de ese país. Retornó a Filadelfia en 1872, donde presentó su reporte y el mapa de reconocimiento de la isla.

A partir de 1873 , y durante tres años, trabajó para el gobierno de Costa Rica. Durante su estancia en este país comenzó a sufrir una malaria severa, y posteriormente una neumonía, lo que le dejó sus pulmones muy debilitados, y lo hizo una fácil víctima de la tuberculosis.

Retornó a los Estados Unidos en 1876, y ese mismo año fue electo miembro de la Academia Nacional de Ciencias. Regresó de nuevo a Santo Domingo con la intención de desarrollar un denuncio minero, pero el clima no le favoreció y su enfermedad progresó rápidamente, de modo que en abril de 1878 regresó a los Estados Unidos. Pasó las últimas semanas de su vida adecuando parte de sus manuscritos para que pudieran ser publicados. El 30 de mayo de ese mismo año falleció y fue sepultado en el cementerio de Woodland, cerca de Filadelfia. Evidentemente no tuvo el tiempo necesario para adecuar sus escritos, ejemplo de esto es un manuscrito, a puño y letra de Gabb, que ha permanecido inédito en la biblioteca del Servicio Geológico de Estados Unidos (USGS). Gómez (1977) cita este documento con fecha 1895-1910, sin embargo en la copia que consultamos, era claro que fue hecho en 1874 , lo cual corresponde mejor con la cronología histórica, incluyendo su muerte en 1878. Este documento (Gabb, 1874), contiene una serie de observaciones y comentarios que no están incluidos en las publicaciones formales, por lo que en el desarrollo de este trabajo, haremos una serie de citas textuales traducidas.

\begin{tabular}{|c|c|c|c|c|c|}
\hline & $\begin{array}{r}\text { P } \\
\text { Bas }\end{array}$ & $\begin{array}{l}\text { CUAD } \\
\text { blicaciones de } \\
\text { da en Dall (190 }\end{array}$ & $\begin{array}{l}\text { RO } 1 \\
\text { Nilliam M. } \\
\text { 8) y Góme }\end{array}$ & $\begin{array}{l}\text { Gabb } \\
(1977)\end{array}$ & \\
\hline Año & \# Publ. & Paleontología & $\begin{array}{l}\text { Geología } \\
\text { Regional }\end{array}$ & Minería & Otros \\
\hline 1859 & 2 & 2 & & & \\
\hline 1860 & 11 & 11 & & & \\
\hline 1861 & 10 & 9 & 1 & & \\
\hline 1862 & 5 & 5 & & & \\
\hline 1864 & 6 & 5 & & 1 & \\
\hline 1865 & 2 & 2 & & & \\
\hline 1866 & 4 & 3 & 1 & & \\
\hline 1867 & 2 & & & 1 & \\
\hline 1868 & 6 & 4 & 2 & & \\
\hline 1869 & 7 & 7 & & & \\
\hline 1871 & 2 & & 2 & & \\
\hline 1872 & 5 & 3 & 2 & & \\
\hline 1873 & 3 & & 3 & & \\
\hline 1874 & 3 & & 3 & & \\
\hline 1875 & 7 & 2 & 4 & & 1 \\
\hline 1876 & 3 & 2 & & & 1 \\
\hline 1877 & 1 & & 1 & & \\
\hline 1878 & 1 & & & & 1 \\
\hline 1881 & 3 & 3 & & & \\
\hline 1882 & 1 & 1 & & & \\
\hline 1893 & 1 & & 1 & & \\
\hline 1895 & 2 & & 2 & & \\
\hline 1911 & 1 & & 1 & & \\
\hline 1913 & 2 & & & & 2 \\
\hline 1969 & 1 & & & & 1 \\
\hline 1978 & 1 & & 1 & & \\
\hline Total & 91 & 59 & 24 & 2 & 6 \\
\hline
\end{tabular}

Nota: de las 91 publicaciones, 8 son traducciones al español 
Durante sus veinte años de trabajo profesional en las ciencias geológicas -desde 1859 hasta 1878- produjo 91 publicaciones, incluyendo las póstumas y las traducciones (Cuadro 1). Sobre Costa Rica se pueden contabilizar por lo menos 5 trabajos geológicos originales y más de 10 reproducciones, traducciones y publicaciones no geológicas (Apéndice 1)

Su trabajo en Costa Rica significó un tremendo desgaste en su salud, e incluso anímicamente se percibe el feroz esfuerzo que tuvo que hacer para soportar largas caminatas en un clima mucho más húmedo y agreste de lo que estaba acostumbrado. En tres años de trabajo (18691871) hizo la geología de 38000 kilómetros cuadrados, en la isla de Santo Domingo, lo que significa tres cuartas partes del territorio de Costa Rica, en tanto que en Costa Rica cubre 8000 kilómetros cuadrados. Como él mismo lo describe: "En un país abierto, con buenas rutas de viaje, yo pude fácilmente haber completado en tres o cuatro meses toda la exploración geológica que necesitó diez y siete meses, del trabajo más duro que nunca hice en mi vida". En el mismo párrafo escribió en forma mucho más emotiva: "Este no es el lugar para hablar de trabajo agotador y sufrimiento de estar expuesto por semanas a lluvias continuas, cruzando ríos crecidos bajo el riesgo de nuestras propias vidas, de fiebres; en breve de todos los placenteros episodios inevitablemente conectados con el trabajo en bosques tropicales primarios" (Gabb, 1875). Su última frase lo delata, sin embargo, como un aventurero, pues a pesar de las penalidades y sufrimientos del trabajo, da a entender que los placenteros episodios borran lo anterior. Ineludiblemente tenía que ser un aventurero y amar la ciencia, pues de otra manera nunca hubiera venido a países tan poco conocidos en la época, como él mismo lo dice refiriéndose a Costa Rica: "...el país más desconocido de cualquier parte de América Central..." (Gabb, 1875).

En sus años de andanzas por las selvas de Talamanca, dejó un descendiente, cuya madre era cuñada de John Lyon, quien era un estadounidense que vivía en esos parajes desde 1856, y que atendió a Gabb durante su permanencia. Lyon era muy respetado entre los indígenas y por su intervención llevó al hijo de Gabb en 1886 a San José, donde fue educado por cuenta del gobierno de la República, obtuvo el Certificado de Madurez en el Liceo de Costa Rica y después de algunos problemas retornó a Talamanca (Petermann, 1877). Posteriormente sirvió como interprete y así ayudó a otros investigadores como Sapper y Pittier (Ferrero, 1978).

\section{CRÍTICAS A SU TRABAJO PALEONTOLÓGICO DE SANTO DOMINGO}

No todo han sido elogios para este pionero de la geología latinoamericana. Recibió críticas muy fuertes respecto a su trabajo paleontológico de Santo Domingo, por parte de Henry A. Pilsbry, quien hizo una extensiva revisión de más de cien páginas, donde textualmente escribió: "Las descripciones de Gabb dan evidencia de haber sido hechas de prisa y con el uso de lentes de poco aumento solamente. Las dimensiones de las conchas fueron a menudo omitidas, y cuando fueron dadas son casi invariablemente inexactas, como si fueran estimadas más que realmente medidas. Hay muchos errores tipográficos, debido a la circunstancia de que la publicación fue impresa antes de su partida a Costa Rica. Él no vio las pruebas. Nosotros hacemos notar estas cosas meramente para justificar ocasionales discrepancias entre las descripciones originales y las notas descriptivas suplementarias encontradas en esta revisión" (Pilsbry, 1922, p. 307).

Pilsbry tuvo acceso a las colecciones originales de fósiles de Gabb, que éste había entregado a la Academia Natural de Ciencias de Filadelfia, y con base en eso hizo una revisión junto con C. W. Johnson. Incluso resalta que desempacó personalmente algunas muestras de las que el mismo Gabb había empacado en Santo Domingo, pues afirma que muchos de las conchas que son puestas como nuevas [se refiere Pilsbry a su propia publicación] habían sido determinadas incorrectamente por Gabb, otras "...fueron seleccionadas de paquetes, que por su condición y las fechas de periódicos usados como envolturas, aparentemente no habían sido abiertas desde que 
fueron empaquetadas en Santo Domingo" (Pilsbry, 1922, p. 306).

Pilsbry afirmó que ".Gabb no fue capaz de dibujar sus especies" (p. 305), lo cual consideramos que es incorrecto, pues al revisar las publicaciones de Gabb de 1881 (a y b), encontramos más de 150 dibujos de los moluscos de Santo Domingo y Costa Rica. Aparentemente Pilsbry no vio este trabajo, que aunque póstumo, recogió justamente gran parte de la información necesaria para las comparaciones faunísticas de las nuevas especies. Otra de las críticas de Pilsbry con respecto al aporte paleontológico de Gabb en Santo Domingo, fue la falta de ubicación detallada de las localidades o afloramientos donde se encuentran los fósiles. Textualmente dice: "Con dos o tres excepciones, ninguna de las etiquetas contenía indicación de localidad u horizonte [refiriéndose a capa estratigráfica] más que Santo Domingo". Definitivamente, tanto el trabajo regional de 1873 como los de 1881, carecen de una buena localización, que incluso es uno de los aspectos que ha dificultado la correlación de algunas localidades fósiles. Posteriormente se hará una explicación más extensa sobre los problemas de ubicación de la localidad fosilífera de Zapote, en las cercanías del río Reventazón.

De estas críticas se rescata que, a pesar de todo, el trabajo de recolección de materiales fosilíferos fue útil incluso para Pilsbry, y que sin duda, Gabb era un geólogo de campo que disfrutaba mucho más su trabajo-aventura en sitios alejados, que hacer labores minuciosas en las cuatro paredes de un laboratorio. Esta actitud característica de Gabb se puede interpretar también de su biografía, pues prefirió emprender otra actividad de campo en Costa Rica, antes de terminar sus publicaciones de Santo Domingo. Emprendió una nueva aventura en Santo Domingo, sin concluir sus escritos sobre Costa Rica. No es sino hasta después de verse obligado a regresar a Estados Unidos por el rápido deterioro de su salud, que adecua algunos escritos para que pudieran ser publicados. Evidentemente no tuvo el tiempo necesario para terminar este trabajo, pues murió muy rápidamente; razón por la cual todavía hoy estamos discutiendo aspectos inconclusos de sus trabajos geológicos.

\section{LA GEOLOGÍA DE COSTA RICA VISTA POR WILLIAM GABB}

Gabb lamentó no haber podido seguir sus observaciones en el Pacífico de Costa Rica, empero no sólo se limitó a la Talamanca, el mismo escribe: " En adición a esto [el estudio de la Talamanca], crucé el país, de océano a océano, varias veces entre Limón y Punta Arenas, o Puntarenas, hice una excursión dentro de Nicoya y algunas otras más pequeñas en el interior, incluyendo visitas a los dos volcanes Irazú y Barba." (Gabb, 1874).

Su comparación de la morfología de las costas resulta muy acertada: "La costa atlántica es cóncava, con dirección sureste, con pocas irregularidades como bahías y promontorios, una playa muy continua de arena bordeando una sucesión de pantanos y lagunas. El lado Pacífico, por el contrario es mucho más irregular con líneas curvas amplias profundamente indentadas, por los golfos de Nicoya y Dulce... " (Gabb, 1874). Estas observaciones son muy interesantes, pues destacan justamente las diferencias entre la costa en un margen tectónicamente pasivo, como es la costa caribeña, con otro como el Pacífico, controlado por la zona de subducción de la placa del Coco bajo la Caribe. Valga recordar que el advenimiento de la tectónica de placas como parte integral del paradigma geológico no ocurre hasta la segunda mitad del siglo XX.

Sobre el pico de Herradura (se refiere al cerro Turrubares, del que ya se discutía si era o no un volcán, y aún en este siglo se afirmaba lo mismo) Gabb (1874) afirma que no es un volcán. Textualmente escribió: "Herradura ha sido nombrado por la mayoría de escritores como un volcán, como yo no veo razón para su suposición, más allá que por su altitud y el hecho que está en un país de volcanes." (Gabb, 1874).

Hizo el ascenso a algunos volcanes de la Cordillera Volcánica Central y se refirió a las calizas de los montes de Candelaria, que corresponden con lo que ahora se llama Calizas de Parritilla, del Eoceno Superior. No puede explicar sin embargo, la presencia de materiales netamente volcánicos (escoria, pómez, obsidiana) cubriendo partes entre el volcán Irazú y Candelaria (Gabb, 
1874, p. 38). Acá se refiere a las ignimbritas de San Gabriel y alrededores, que ahora se consideran el producto de un volcanismo cuyos centros de emisión estaban ubicados más al sureste de la Cordillera Volcánica Central, y que ahora sabemos que son el producto de un arco volcánico activo en el Plioceno (Denyer \& Arias, 1991).

Se percató de la amplia cobertura de depósitos volcánicos: "Todo el país, desde Sapote [localidad ubicada unos $20 \mathrm{~km}$ al noreste de Turrialba, de la que posteriormente se darán más detalles] a la cima de los montes del Aguacate, excepto las montañas altas que bordean el valle en el sur [probablemente los cerros de Escazú], pueden ser descritos fácilmente como cubiertos por una capa de ceniza volcánica..." (Gabb, 1874, p. 34). Esto lo explicó como producto de conos volcánicos que sobresalen de la planicie: "En el lado del camino, corta el lado de la colina en el cruce del Río Grande, opuesto a "Garita" o vieja aduana, está una buena ilustración de uno de estos volcanes infantiles" (Gabb, 1874, p. 43).

Gabb también realizó una rápida incursión en la Península de Nicoya, cerca de Lepanto, donde describió lutitas metamorfoseadas, con vetas de carbón en isletas del Golfo. Probablemente vio afloramientos de la hoy conocida Formación Loma Chumico, que existen en las cercanías de Lepanto y Jicaral, y cuya edad es del Cretácico Superior. Extraña sin embargo, que Gabb no hizo ninguna referencia a las rocas ígneas pertenecientes al Complejo de Nicoya, que por su extensión son la unidad geológica más importante en la Península. Un atenuante a esta omisión sería que justamente en el sector de Lepanto y Jicaral, los afloramientos de basaltos están cubiertos por las rocas sedimentarias que sobreyacen al Complejo, sin embargo el texto no es explícito con respecto al recorrido (Gabb, 1874), por lo que debemos concluir que: o no vió, o no reconoció los basaltos del Complejo de Nicoya.

\section{LA GEOLOGÍADE TALAMANCA SEGÚN GABB}

En la primera frase de su informe geológico esbozó una completa confianza en sí mismo, revelando en quien la escribió, cierta arrogancia, propia de aquel académico de las Ciencias de la Tierra que confronta la Geología del Terciario, textualmente Gabb (1895) dice: "Considerada en su conjunto la estructura geológica de la región estudiada es muy sencilla".

Cerca del río Yorkín describió la existencia de lutitas y areniscas y un par de millas arriba "...buenas exposiciones de un conglomerado grueso, con rumbo N25 W, que buza NE10 .." (Gabb, 1874, p.21). Consideramos que está hablando de la Formación Río Banano o Gatún, cubierta por los conglomerados de la Formación Suretka. Abajo de la desembocadura del río Izgui, las rocas contienen numerosos fósiles, los que reconoce de edad Mioceno, y acá de nuevo creemos que se refiere a la hoy conocida Formación Río Banano.

$\mathrm{Al}$ igual que el cerro Turrubares, el Pico Blanco o Kamuk también había sido descrito como un volcán activo y que sus erupciones habían sido apreciadas por los destellos desde su cima repetidamente. Gabb aclaró que no duda de la existencia de luces, pero éstas deben tener otro origen, como por ejemplo por la quema de la maleza del lugar, lo cual desde la costa podría interpretarse como una erupción volcánica, pues esta montaña tiene una constitución granítica, casi sin micas y con abundancia de hornblenda, "esta roca es decididamente una sienita...", la cual está cortada por diques (Gabb, 1874, p. 9). Vemos en estas descripciones que Gabb comenta con propiedad la mineralogía de las rocas de Talamanca y lo que es más importante, usa el criterio geológico para desechar la idea de la existencia de este volcán, porque claro, este pico estaba constituido por rocas intrusivas, y no existen depósitos volcánicos.

Existía una referencia que indicaba que el período glaciar se extendió en Centro América, específicamente, un trabajo de un naturalista que estuvo en Nicaragua de apellido Belt (Gabb, 1874, p. 11). Gabb conocía esta referencia, por lo que buscó evidencias de un fenómeno parecido en Costa Rica. A este respecto dice: "...esto [se refiere al trabajo de Belt] me indujo a investigar sobre pruebas que comprobaran o desprobaran la teoría... No encontré ningún signo de la presencia 
de hielo aquí, ... no hay evidencia para pensar que esta parte de Costa Rica estuvo más allá del límite del hielo." (p. 11). Cuando interpreta el origen de los sedimentos recientes del río Tilorio [Changuinola] escribió: "No existe prueba más fuerte de la ausencia de hielo, como un elemento entre las fuerzas que han modelado el país..." (p. 22), y entonces especifícó cómo debería ser un material con influencia glacial, textualmente dijo: "El hielo, al igual que un glaciar o iceberg nunca selecciona su material, los depósitos glaciares siempre están hechos de materiales de todos los tamaños y formas, indiscriminadamente mezclados y amontonados o tirados abajo juntos" (p. 23).

Gabb mencionó la actividad sísmica que ocurrió en la región mientras hacía su trabajo en la Talamanca: "Debo mencionar un par de leves terremotos que sentimos mientras llevábamos a cabo nuestras exploraciones. El 10 de agosto de 1873, cerca de las 9 a.m. en Sipurio, sentimos un leve movimiento viniendo desde el SW..." (Gabb, 1874, p. 24 y 25). Este mismo evento sísmico fue sentido por su asistente Martínez, quien menciona además la sacudida violenta de árboles. Otro sismo ocurrió el 8 de octubre, mientras Gabb estaba en Coén, y en este caso el sismo fue lo suficientemente fuerte como para ser sentido en las hamacas. Este sismo ocurrió en la mañana, pues Gabb mencionó que estaba esperando el desayuno. Ya Gabb había sentido otro sismo en marzo de ese mismo año, mientras estaba en San José, aunque en este caso no hace referencia al día.

Hoffstetter et al. (1960) atribuyen a Gabb la nominación de la Serie Plutónica de Talamanca como fue descrita en Gabb (1875), aunque valga aclarar que él no utiliza exactamente esta nomenclatura. Probablemente el espíritu de Hoffstetter et al. (1960) fue hacer justicia, al ser Gabb la primera persona en reconocer la constitución geológica plutónica de la cordillera de Talamanca.

La localidad de Zapote (conocida como "Sapote" en los escritos del siglo pasado) es muy importante dentro de las descripciones de fósiles (Hoffstetter et al. , 1960, p. 294), Gabb incluyó nuevas especies, detalladas y bautizadas en su trabajo publicado postmórtem (Gabb, 1881b). Gabb (1874) describió esta localidad como cerca- na al río Reventazón, en la cual encuentra una sección continua donde afloran calizas, arenicas y lutitas con ocasionales conglomerados, que contienen numerosos fósiles característicos del Mioceno, algunos similares a los de Gatún en Panamá. Incluso, con base en las descripciones de macsrofauna de esta localidad, Hoffstetter et al. (1960) propusieron que esta debe ser la localidad tipo de la Formación Uscari. Con base en el mapa de José Ma Figueroa \& Oreamuno de 1883 (Zúñiga, 1910), se localizó la quebrada Zapote, que comparando con los mapas actuales se interpreta que estaba entre las coordenadas 224 y 228 de latitud y 581 y 586 de longitud, de la hoja topográfica Bonilla (publicada por el Instituto Geográfico Nacional). Suponemos entonces una cercanía entre la quebrada Zapote (probablemente la actual quebrada Lajas) y el lugar del mismo nombre que menciona Gabb (1874, p. 31), el cual estaba sobre el camino. Con base en la descripción de Gabb, la localidad geológica que él indica como Sapote, corresponde con las cercanías de la quebrada Lajas, pues ubica como sigue el lugar: "Abajo de Sapote, sobre el río Reventazón, en la base de la misma colina [un lugar de fuerte pendiente sobre el camino conocido como Sapote], yo tuve la oportunidad de examinar una extensa sección. La distancia horizontal desde Sapote es más o menos cuatro millas, y la vertical no mucho menos que mil pies" (Gabb, 1874, p. 31).

Aguilar (1993) hace referencia a esta localidad geológica como perteneciente a la Formación Uscari, aunque en el mismo texto explica las dificultades de correlación geográfica entre la localidad de Gabb y aquella descrita por ella, por lo que escribe lo siguiente: "Gabb (...), es el primero en hacer referencia a la macrofauna procedente de Sapote (¿Zapote?), la cual aparentemente corresponde con la parte Inferior de la Formación Uscari. Aunque debido a los problemas de nomenclatura y ubicación geográfica esta localidad no ha sido claramente identificada." Ahora, con la localización que hicimos de la quebrada Zapote y las descripciones de Gabb y de Aguilar, nos atrevemos a interpretar que se trata de la misma secuencia sedimentaria, que aunque descrita en otra localidad, es relativamente cercana. 
Gabb destacó la presencia de arrecifes de coral, teoriza sobre el sustrato diciendo: "Los arrecifes, y los depósitos de Antillita ocurren sólo cuando una colina del interior alcanza la costa, y las rocas ofrecen un fondo sólido que permita que el animal coral se construya." (Gabb, 1874 , p. 26). No debemos omitir que ahora se sabe que también pueden existir organismos pioneros que estabilizan un sustrato arenoso o blando, lo que permite la posterior colonización de grupos constructores.

Para rescatar una de las más importantes contribuciones científicas de Gabb, enumeramos en el Apéndice 2 algunas de las nuevas especies de moluscos del Neógeno que existen en Costa Rica y que fueron descritas como especies nuevas por el mismo Gabb, en la que destacan por lo menos 30 especies de gasterópodos, 17 de bivalvos, 2 escapófodos y 1 equinoideo, así como también se han denominado por lo menos tres nuevas especies en honor a Gabb.

\section{EL MAPA GEOLÓGICO DE TALAMANCA}

Este mapa no apareció publicado en ninguno de los escritos consultados, incluso en el manuscrito de Gabb de 1874, hay una nota de la biblioteca en la primera página, que indica el faltante de las figuras que probablemente acompañaban este informe. Sin embargo era conocido por los eruditos de la época. H. Pittier se refiere a este mapa de la siguiente forma en la introducción del libro de Gabb (1895, p. 8): "El mapa geológico de Gabb es hasta hoy la única contribución que poseemos acerca de la constitución geognóstica de la parte meridional de Costa Rica. Es de sentirse que no haya visto aún la luz, junto con una recopilación cuidadosa de los datos en que se funda". Y hasta hoy, ha sido un documento que quedó inédito en copias que hasta cierto punto podríamos llamar caseras, y no es sino hasta la presente publicación que hacemos una reproducción del mapa geológico original de Talamanca (Fig. 2). Este mapa es propiedad de Rafael Oreamuno, como una reliquia familiar. El cual es una copia hecha por Luis Matamoros, quien fue director del Instituto Geográfico. Debido al mal estado de la copia, que incluso estaba pintada, y para que fuera posible entender su significado, se hizo una reconstrucción de los contactos geológicos (Fig. 2), los rasgos geográficos se observan muy difusamente en dicha copia, pero se nota que casi todos los ríos y afluentes de la región estaban marcados y con sus respectivos nombres, probablemente la base geográfica correspondía con algo similar a su mapa geográfico (Fig. 3).

Es también sorprendente que el mapa geológico de Gabb, en su mayoría fue hecho con base en sus propios levantamientos topográficos. Gabb escribió el 30 de noviembre de 1874, el siguiente párrafo: "...Si se exceptúa la línea de la costa próxima a Limón, todo el mapa descansa sobre el valor de nuestras propias medidas... No solo hemos medido el interior, sino que también hemos practicado nuevas medidas y rectificado las de Limón a Boca del Drago, teniendo como base una combinación de las medidas con cadena, y de triangulaciones... Aunque las medidas de este plano no aspiran en sus detalles a una corrección absoluta, puede que sean más exactas que las de muchos países civilizados. La posición de los ríos está bien marcada y su curso exactamente representado..." (En Petermann, 1877). Destaca la exactitud y detalle de la línea de costa, que va desde Limón, prácticamente hasta Bocas en Panamá, nótese también en la Fig. 2, el delineamiento del valle de Talamanca (parte alta del río Sixaola). La base geográfica original se observa en el mapa publicado por Petermann (1877), escala 1:600 000, bajo la consigna de que es copia del mapa de Gabb, Collins \& Martínez. La Fig. 3 muestra este mapa, que aparentemente corrió una suerte parecida al geológico y nunca fue publicado en nuestro país. No es claro si este mapa, que presentamos en la Fig. 3, es una copia fidedigna del mapa de Gabb, pues el área que abarca es bastante mayor a lo que se supone debió contener el mapa original de Gabb. Petermann debe haber hecho algunas actualizaciones, como destaca de la leyenda de este mapa, donde se nota que el trazo de la línea ferroviaria está actualizada hasta 1877 . Interpretamos entonces, que el mapa de Petermann usó como base el de Gabb en lo que respecta a Talamanca, incluyendo la línea de costa caribeña y, el resto fue tomado de otros trabajos cartográficos. 
Gabb dibujó contactos geológicos, que aunque groseros, indican una visualización clara de la geología de la cuenca de Limón. Es decir, la existencia de rocas sedimentarias miocenas, intruidas por las rocas plutónicas que conforman el núcleo de la cordillera de Talamanca, y que

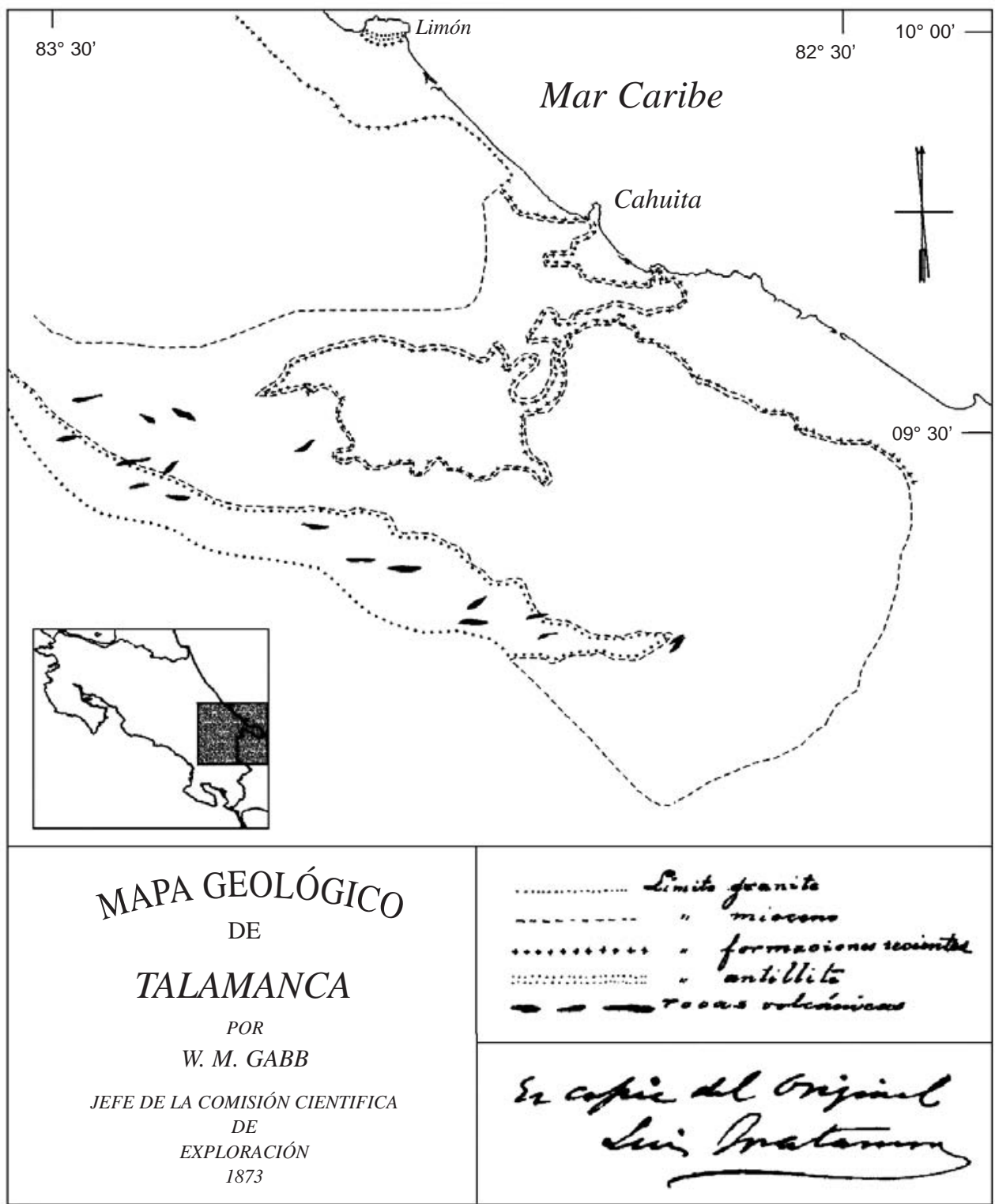

Fig. 2: Mapa Geológico de Talamanca. Esta figura es una copia del mapa que redibujó Luis Matamoros. El cajetín se redibujó conservando las características originales. La firma de Matamoros se conserva de la copia original de este mapa, aunque parcialmente retocada en computadora, para que fueran legibles, de la misma forma que la simbología, que dice: Límite granito, mioceno, formaciones recientes, antillita y rocas volcánicas. Las líneas de coordenadas eran visibles pero no así los números, los cuales interpretamos por su posición geográfica comparándola con un mapa geográfico actual. Se incluye un mapa de localización aproximada. La distancia entre las coordenadas $82^{\circ} 30^{\prime}$ y $83^{\circ} 30^{\prime}$ es de unos $110 \mathrm{~km}$. 


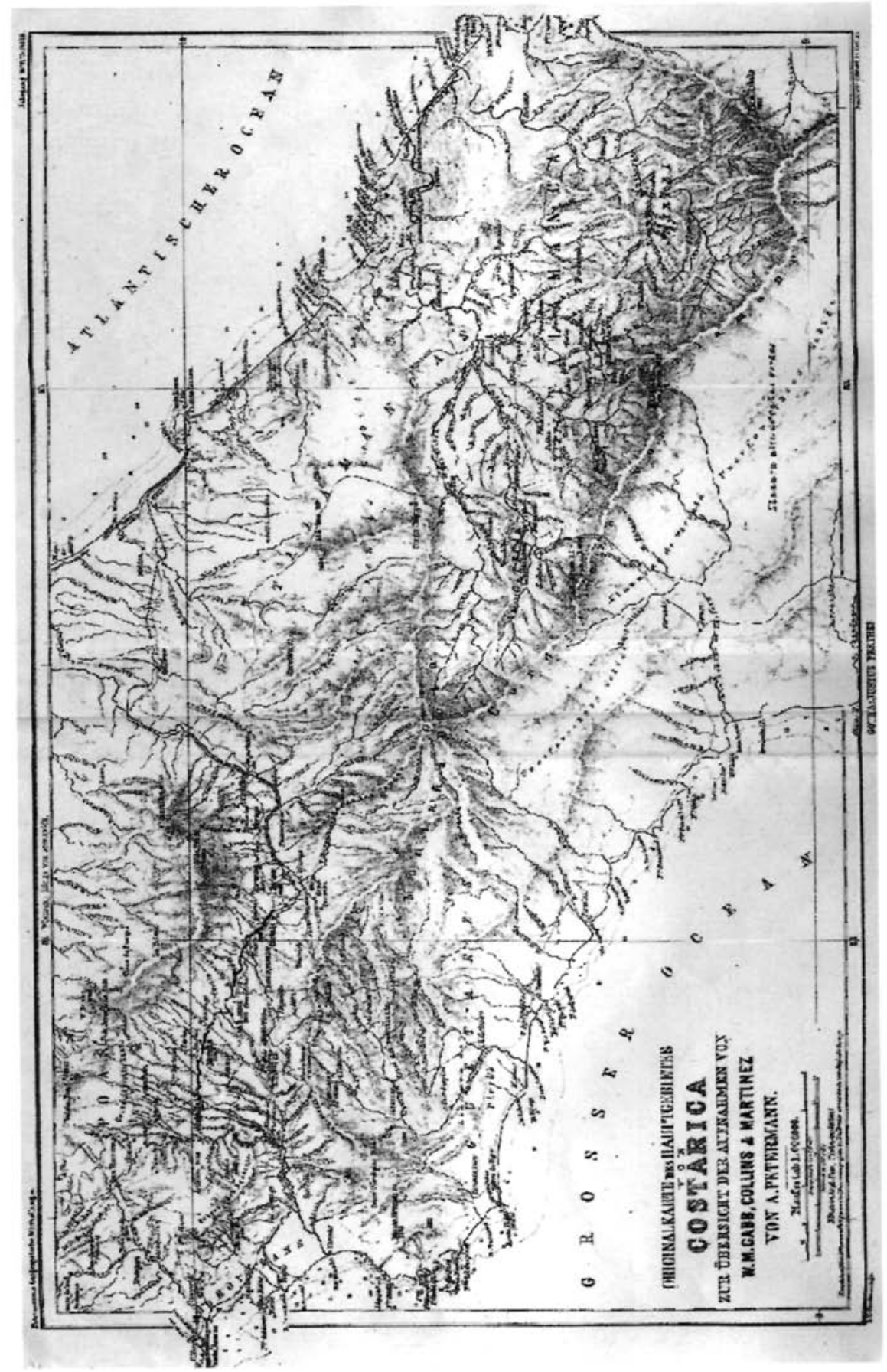

Fig. 3: Mapa Geográfico de Gabb, que apareció publicado en Petermann (1877). La leyenda, traducida del alemán dice: "Mapa original del territorio principal de Costa Rica, como resumen de los levantamientos de W.M. Gabb, Collins \& Martínez. Escala 1:600 000 [Esta reproducción ha variado la escala]. Escala gráfica en millas alemanas y kilómetros. Alturas en pies ingleses. Profundidades en brazas. Ferrocarril (mediados 1877): terminado, en construcción, en proyecto; solamente funciona en el trecho Alajuela-Cartago". 
causaron el metamorfismo de parte de los sedimentos. Cartografíó las "antillitas" post-pliocenas, refiriéndose a los corales fósiles; este nombre había sido acuñado por el mismo Gabb, con el objetivo de distinguir entre la tiza y la "caliza de costa", la cual "fue formada a una considerable distancia de la línea de costa como un borde arrecifal" (Gabb, 1873, p. 105). Como un hecho curioso, destacamos que el mapa geológico de Costa Rica, publicado por la Dirección de Geología, Minas e Hidrocarburos, en 1982 -es decir: más de un siglo después del de Gabb-, ni siquiera hace referencia a los arrecifes plio-pleistocenos que afloran en los alrededores de la ciudad de Limón, Cahuita, Puerto Viejo y Punta Mona.

Con respecto a la presencia de corales fósiles en las "antillitas"; textualmente dice: "La geología de la región de la costa de Talamanca es muy simple. En pocos sitios, la vecindad de la laguna de Boca del Toro, punta Mono, punta Manzanillo y Cajuita [conocida actualmente como Cahuita], hay exposiciones de coral de roca, llamada por mí Antillita en Santo Domingo. No difieren en origen o carácter de las calizas post-Plioceno de Jamaica, Santo Domingo, Cuba, las Bahamas." (Gabb, 1874, p. 25). Es interesante que las Antillitas fueron descritas por Gabb en diversas localidades, sin embargo en el mapa geológico sólo las ubicó en Limón, dejando por fuera Cahuita, Puerto Viejo, Manzanillo y Punta Mona. Lo único que parece posible es que considerara que estos afloramientos eran demasiado pequeños para ubicarlos en un mapa a esa escala.

Los mapas geológicos como herramienta científica que produce un modelado geométrico de la realidad había sido usado desde hacía más de un siglo antes. La primera propuesta de mapa geológico fue hecha en 1683 por L.M. Lister y el primer mapa geológico se publicó en 1743 en Inglaterra, y en Norte América en 1817 (Geikie, 1962, p. 458). Es obvio, al observar el mapa geológico de Talamanca (Fig. 2), así como el de Santo Domingo (Gabb, 1873), que esta herramienta era dominada brillantemente por Gabb. Por supuesto que los mapas recientes dan un detalle muchísimo mayor, pero el concepto general de la geología de la región es a grosso modo, igual. La ausencia de estructuras geológicas en el mapa, es aparentemente una carencia de la época, como se explicará posteriormente al hacer la comparación de sus trabajos, dentro de los paradigmas que dominaban la conceptualización del modelado geológico en la época.

\section{SOBRE LOS YACIMIENTOS MINERALES DE TALAMANCA}

La referencia que hizo Gabb a la presencia de oro es muy clara: "...la existencia de oro aquí es más que nada de interés científico que económico", las minas de oro son una falacia geológica, como él mismo escribió: "Es suficiente decir aquí que tales minas no existen, para lo que hay suficientes razones geológicas..." (Gabb, 1875). Encontró sin embargo, algunas vetas de cuarzo con algunas cantidades de oro, en general con muy difícil acceso (Gabb, 1895, p. 68). Es muy categórico en la siguiente frase: "Las supuestas minas de oro de Tisingal no pueden haber existido en el territorio explorado por mí."

Se refirió a los extensos depósitos de magnetita en la costa, como "arena magnética de hierro" y menciona la localidad de Puerto Viejo, donde efectivamente sabemos que playa Negra es de un alto contenido de magnetita. Los describió como de grano fino y mucha pureza, e hipotetizó sobre su fuente, que: "debe ser bajo el mar, probablemente desde un afloramiento submarino de rocas graníticas" (Gabb, 1874, p. 28), además notó los límites abruptos entre las arenas magnetíferas con las blancas. Esto es correcto, pues recordemos que hacia el sureste las playas arenosas terminan contra el promontorio de Puerto Viejo, y son básicamente el producto de la erosión de los arrecifes. Los estudios recientes más bien consideran que la magnetita proviene de la erosión del mineral presente en la Formación Río Banano, y que ésta a su vez contenía la magnetita como un producto de erosión de los intrusivos que conforman la Cordillera de Talamanca (Cortés et al., 1998).

Con respecto a los depósitos de carbón, indicó que existe una faja continua desde la desembocadura del río Changuinola hasta Matina (Gabb, 1895). Específicamente menciona la localidad de 
Watsi, otro pequeño tributario del Tiliri, y la cara norte de las montañas Negro, en la cabecera de Hone Creek (Gabb, 1874, p. 24). Por supuesto se refiere a los depósitos de carbón intercalados en los sedimentos de la Formación Río Banano, que recientemente en este siglo, en la década de los ochentas fueron investigados por RECOPE, en los que los estadounidenses habían tenido interés desde 1850 (Ramírez, 1985). La conclusión de este geólogo del siglo pasado ya había sido muy concluyente y expresada de la siguiente forma: "Este carbón se averiguó ser de tan mala calidad como el de la Carpintera y absolutamente impropio para combustible" (Gabb, 1895, p. 69).

La existencia de petróleo fue reportada en un solo punto en Alto Telire, pero Gabb recomienda ser precavidos con base en las "desastrosas experiencias" de California.

Resumiendo, Gabb concluye que la Talamanca no contiene riquezas minerales, lo que en la época constituyó el desencanto de aquellos que lo habían traído para localizar, apropiarse y explotar las riquezas de Talamanca, con lo cual talvez hemos tenido suerte, pues todavía conservamos la gran riqueza que representa esta región con su abundante flora y fauna.

Pero, ¿qué ha pasado con el desarrollo del conocimiento cien años después? Tenemos que contestar esta pregunta diciendo que, a pesar de grandes esfuerzos, las conclusiones siguen siendo las mismas, lo que le da un punto más a su favor como geólogo, es decir, han sido válidas por más de una centuria.

\section{EL TRABAJO PIONERO DE GABB DENTRO DE UN CONTEXTO HISTÓRICO Y DEL PARADIGMA GEOLÓGICO DE SU ÉPOCA}

Hemos mencionado que en la segunda mitad del siglo XIX empezaron las observaciones científicas serias en Costa Rica, algunas de ellas relacionadas con la prospección de yacimientos minerales, y las más, con respecto a fenómenos naturales. Es Gabb el primero que investiga geológicamente el territorio con objetivos definidos, y presenta una visión global de una región, junto con un mapa geológico, y además, un esbozo general de la geología de todo el país, hasta donde lo pudo conocer, en momentos en que Costa Rica apenas despegaba económicamente, y el oro aportaba un impulso nada despreciable. La construcción de grandes obras, en este caso el ferrocarril, viene a ser el detonante indirecto del arribo de Gabb. Aún no existían los institutos de investigación y enseñanza importantes, que no vendrían a desarrollarse sino hasta un decenio y medio después. Geológicamente hablando, tiene sentido el bautizo que hacen Alvarado et al. (1991) al período entre 1852 y 1887, como "etapa pregeológica" en Costa Rica, Coronado (1997), considerando la actividad científica en general, considera la etapa de 1843 a 1887, como de "científicos cometas", donde científicos extranjeros visitaron el país para establecer un registro de lo que había.

Es paradójico que los trabajos pioneros de Gabb no influyeran decididamente en el paso a una "etapa de inicio y avance geocientífico", sino que más bien permanecieran muy olvidados; por ejemplo: su mapa geológico de Talamanca permanece inédito y no es sino hasta la presente publicación que se hace una reproducción de dicha cartografía. Conceptos tales como la cartografía de las "antillitas", ampliamente discutido previamente, no es incluido aún en mapas geológicos publicados un siglo después. Por lo tanto, el trabajo de Gabb, aunque pionero y admirable, no llega a ser continuado rápidamente y por lo tanto el desarrollo de las ciencias geológicas en Costa Rica queda parcialmente paralizado. Esto probablemente es debido a que no existía ningún costarricense con una formación geológica lo suficientemente sólida como para seguir los pasos del maestro, por lo que la "etapa de inicio y avance geocientífico" como denomina Alvarado et al. (1991) al siguiente período de evolución de la geología, es demasiado largo, abarcando desde 1888 hasta 1962. Destacan, en este segundo período, J.F. Tristán, A. Alfaro y C. González Víquez, cada uno de los cuales dejó un gran legado, y todos ellos se destacaron por su gran entereza, deseos de conocimiento y capacidad científica, pero desgraciadamente no tenían una educación formal en la Geología, lo que impidió que se siguieran haciendo 
mapas geológicos con columnas estratigrafías detalladas, o que impulsaran la creación temprana de un Servicio Geológico.

Por otro lado, podemos imaginar que la historia podría haber sido muy diferente si las investigaciones de Gabb hubieran aportado información interesante desde un punto de vista económico, es decir si hubiese encontrado sitios con posibilidad de explotación de algún mineral, pues esto podía atraer una especial atención sobre los temas geológicos, y de hecho el interés comercial hubiera dado un cambio de rumbo a la historia de la geología. Es más, el desarrollo de Talamanca hubiera sido muy diferente, pues recordemos que incluso cuando Gabb a final de cuentas fue pagado por el gobierno, los Keith siempre siguieron muy de cerca su trabajo de exploración, e incluso M. Keith tenía cierta influencia en las decisiones que se tomaron al respecto, como sobresale incluso en la carta que Gabb envía al presidente de la República (Gabb, 1895), donde dice que sigue las instrucciones del señor Keith al enviar las muestras recolectadas al Instituto Smithsoniano.

Al crearse el Museo Nacional en 1887, se subsanó una falencia que Gabb enfatizó particularmente en su carta al Presidente Guardia, cuando justificaba la exportación de sus prolijas colecciones de fósiles a Washington. A propósito de estas colecciones, hasta donde hemos podido averiguar, no retornaron a Costa Rica. En una carta en nuestro poder, el señor William Cox, asistente archivista del Smithsoniano, dice en 1992, que "...Gabb colectó especímenes etnológicos y zoológicos, los que el donó al Smithsoniano... Nosotros no tenemos publicaciones, mapas, ni otros materiales creados por Gabb durante su exploración en Talamanca." Nótese que no menciona las muestras geológicas y que según la carta-prólogo que Gabb envió al presidente Guardia (Gabb, 1895) y, serían entregadas de nuevo al Gobierno, cuando éste lo solicitara, en su lugar el señor Cox indica que son donaciones de Gabb, al Instituto Smithsoniano.

Felizmente Gabb se dedicó a la clasificación de las muestras paleontológicas, la cual nos entregó en su publicación póstuma de 1881b, aunque como se puede rescatar de Pilsbry
(1922), fue algo que no terminó al menos con los fósiles de Santo Domingo, y gran parte del material quedó empacado por más de cuarenta años, por lo que podemos presumir que algo parecido debe haber sucedido al material fosilífero procedente de Costa Rica, y quizá todavía haya algo o gran parte de este material perdido.

Nos interesa, además, juzgar el trabajo de Gabb a la luz del paradigma geológico de su entonces. A pesar de que recientemente se ha dicho que el concepto de paradigma que definió Kuhn (1962) es extremadamente vago y variable, tanto como alcanzar hasta veintitrés diferentes significados (Advocate, 1998), nos adherimos a la siguiente definición dada por Kuhn: "Considero a los paradigmas como realizaciones científicas universalmente reconocidas que, durante cierto tiempo, proporcionan modelos de problemas y soluciones a una comunidad científica."

Para la época en que Gabb viene a Costa Rica, ya se habían zanjado definitivamente las principales divergencias científicas entre los neptunistas y los plutonistas. Es muy evidente que Gabb conocía bien el paradigma plutonista, cuando reconoce que las rocas sedimentarias que ha encontrado han sido intruidas y metamorfoseadas por los intrusivos que conforman el núcleo de la cordillera. Una sólida conceptualización le permite discernir el plutonismo del volcanismo. En el mapa geológico (Fig. 1), resulta un tanto extraño que las rocas volcánicas mapeadas aparecen como figuras alargadas que dan la idea de diques intruyendo tanto las rocas sedimentarias miocenas como las rocas plutónicas (de las cuales no especifica la edad geológica). La falta de un "corte geológico transveral" nos impide sacar una conclusión sobre cuál era la idea de Gabb sobre la posición relativa de las rocas volcánicas, solo hay una mención en el texto sobre los diques, que indica que no son de composición sienítica como en Santo Domingo, sino que son pórfidos (Gabb, 1895, p. 43). Podemos deducir, basándonos en los conceptos de la época, que Gabb debió asociar estos afloramientos volcánicos al proceso formador de montañas, pues justamente James Hall, uno de sus maestros, consideraba que en las depresiones de acumulación de sedimentos se daban fracturas y adelgazamiento, 
causados ambos por el curvamiento y el consecuente plegamiento de capas sedimentarias y esto podía provocar la introducción de materia fluida o semifluida, produciendo los diques asociados (tomado del resumen que hacen Mather \& Mason, 1970), que nosotros interpretamos, era el trasfondo conceptual en que Gabb basó esta parte de su cartografía geológica.

En las litologías sedimentarias encontramos cierta discrepancia, en cuanto a la presencia o no de rocas metamórficas. En la traducción al español (Gabb, 1895) se lee lo siguiente: "Por encima de las sienitas, muy trastornado por ellas en las cordilleras más altas y doblado en complicadas series de pliegues en las colinas inferiores, se nota luego un espeso depósito de conglomeraciones, areniscos, esquistos y escasa proporción de calizas. Los esquistos superan mucho por su abundancia á los demás miembros del grupo ..." En este párrafo destaca la presencia de esquistos, que se definen como una roca de origen metamórfico, de la cual no se tiene noticia, hasta el momento, que indique su presencia en Costa Rica, pues de acuerdo con los paradigmas actuales y la historia geológica de Costa Rica, no existen rocas de un metamorfismo de alto grado, como serían justamente gneises y esquistos. Después de revisar un poco más detalladamente los escritos de Gabb, encontramos que aparentemente es un problema de traducción del término "shale", que no debe confundirse con "schist", pues el primero se refiere a una roca sedimentaria de grano fino conocida en español como lutita, mientras que el segundo es una roca metamórfica, que debería existir únicamente en áreas de metamorfismo regional de alto grado y que se traduciría propiamente como esquisto. Incluso en un diccionario inglés-español, (I.C.R.M., 1963) se traduce el término shale como esquisto arcilloso. En un texto que revisamos directamente del inglés Gabb (1875, p. 201) dice: "Estas rocas del Mioceno estan constituidas principalmente de conglomerados y lutitas (shales) finas, con ocasionales capas de arenisca, y un poco de caliza."

Incluso para Gabb era muy clara la inexistencia de un metamorfismo regional, respecto a lo cual arguye lo siguiente: "No vi en ningún lado la más ligera aproximación a una estructura gnéisica, o cualquier otro signo que pudiera indicar un origen metamórfico para la masa [de rocas graníticas]..." Gabb, 1875, p. 200). Posteriormente también afirma: "Cerca a los granitos las rocas sedimentarias están ampliamente metamorfoseadas, y en la mayoría de los casos su estratificación está completamente destruida." (Gabb, 1875 , p. 201), lo que denota una clara observación del metamorfismo de contacto, producido por el calor del intrusivo de Talamanca. Gabb no utiliza el término "metamorfismo de contacto" ya que la distinción clara entre la transformación de las rocas por metamorfismo regional y de contacto se atribuye a A. Lossen en 1884 (Mather \& Mason, 1970).

Estratigráficamente Gabb dominaba muy bien las sucesiones, incluso se da cuenta de que los sedimentos desaparecen bajo la capa de detritos provenientes del volcán Turrialba (Gabb, 1874, p. 33), indicando un concepto claro de superposición estratigráfica. Describe las unidades de roca de Talamanca desde las rocas fosilíferas miocenas hasta las calizas arrecifales cuaternarias. No hace una distinción, sin embargo, de edades entre las rocas sedimentarias del Terciario, sino que denomina a todas rocas miocénicas, olvidándose por completo del Eoceno, Oligoceno y Plioceno, pues de hecho hay rocas y fósiles de estas edades en la estratigrafía de Talamanca. Creemos haber encontrado la respuesta a esto en su publicación sobre la geología de Santo Domingo (Gabb, 1873, p. 96-97), donde dice: "La edad geológica de las Indias Occidentales terciarias ha sido profunda y hábilmente discutida por autoridades tan competentes que debería ser innecesario que yo reabriera este tema. J.C. Moore, Geo. B. Sowerly, Dr. P.M. Duncan, R.J.L. Guppy, Robert Etheridge, y Sir Robert Schomburgk, todos han contribuido al fondo general de nuestro conocimiento, y han estado únanimemente de acuerdo en colocar la mayor parte de los estratos fosilíferos, incluyendo todas las capas de Santo Domingo en el Terciario Mioceno".

Por lo tanto, Gabb estaba convencido de que todas las rocas sedimentarias de las Indias Occidentales, lo que según la nominación de la época incluía Costa Rica, eran de edad miocena. Incluso se nota el disgusto de Gabb en el párrafo 
siguiente al citado, donde se refiere a una publicación corta de Conrad, que fue publicada en 1853 en la Academia de Ciencias de Filadelfia, donde aparentemente hacía referencia a otras edades, pues más adelante Gabb escribió: "Pero todavía después, él [se refiere a Conrad] repite la afirmación de la edad Eoceno ("Oligoceno") de los estratos de Santo Domingo en tal manera como para demandar una igual refutación, mucho más especialmente desde que el Señor Conrad es el mejor informado de las autoridades sobre el Terciario americano." Valga recalcar que en Santo Domingo efectivamente existen rocas del Eoceno y Oligoceno, sobreyacidas por los sedimentos miocenos (Lewis \& Draper, 1990).

De los párrafos anteriores, incluyendo las traducciones, se deduce que Gabb no esperaba otra cosa que encontrar capas sedimentarias miocenas en el Caribe costarricense, y creemos que eso fue precisamente lo que empañó las interpretaciones que hizo Gabb sobre las edades de los sedimentos terciarios de Talamanca. Por otro lado, no debemos olvidar que justamente los mejores macrofósiles, principalmente moluscos que encontramos en Talamanca son justamente del Mioceno, así que este ha debido ser otro factor que influyó en que Gabb globarizara y concluyera que definitivamente todo el sedimentario de la región era Mioceno. Gabb (1875, p. 201) dice: "... yo fui afortunadamente capaz de colectar fósiles en un gran número de localidades esparcidas no solo en la parte más grande de Talamanca, sino también más lejanas hacia el norte y noroeste, en las partes adyacentes de Costa Rica. Esto prueba, más allá de una duda razonable, que las rocas son una extensión del gran depósito Mioceno encontrado no sólo en el istmo propiamente, sino sobre muchas de las islas de las Indias Occidentales."

La claridad en la determinación de la sucesión de eventos geológicos queda plasmado cuando Gabb utiliza el criterio de que la ausencia de rocas intrusivas en el conglomerado (interpretamos que se refiere a los conglomerados de la Formación Suretka), indican que éste se formó antes, o más bien que no había sido denudado, lo que pone en evidencia su carácter de roca intrusiva, que proviene de un nivel cortical más bajo y ha ascendido por diferencia de densidad con las rocas circundantes. Textualmente se refiere a esto de la siguiente manera: "La ausencia de rocas cristalinas en las conglomeraciones es una prueba irrefutable de que al depositarse las últimas, las sienitas y granitos no habían surgido todavía del interior de la tierra; demuestra también que aquellas sienitas se intruyeron desde abajo, y su carácter intrusivo queda absolutamente establecido por el trastorno de los sedimentos en la proximidad de su masa..." (Gabb, 1895, p. 44). Valga aclarar, sin embargo, que la observación de Gabb fue incorrecta, en el sentido de que sí existen rocas intrusivas como parte de los fragmentos que forman el conglomerado. Nótese además en el fragmento transcrito que hace una nueva referencia al metamorfismo de contacto que se había mencionado anteriormente.

Resulta, por demás interesante, que fallas $\mathrm{u}$ otras estructuras geológicas importantes fueran excluidas como parte del mapa geológico de Talamanca. Esto también se nota en el mapa geológico de Santo Domingo (Gabb, 1873), en el que incluye dieciocho perfiles geológicos donde se describen muy bien el plegamiento de las capas sedimentarias, basculamientos y discordancias regionales, pero ninguna falla geológica corta los estratos, aunque en los mapas recientes de Lewis \& Draper (1990), se indican fallas oeste-noroeste de más de $100 \mathrm{~km}$ de longitud. Destaca, sin embargo, que los perfiles de Gabb muestran un claro dominio del principio estratigráfico de superposición, p.e. los estratos de mayor inclinación constituyen la base de la secuencia sedimentaria y están sobreyacidos por estratos más jóvenes, con ángulos de inclinación más bajos. Por otro lado sería de suponer que Gabb conocía complicaciones estructurales serias, al haber consumido el grueso de su carrera en el occidente de los Estados Unidos, por lo tanto en los párrafos siguientes discutiremos los conceptos tectónicogeológicos de Gabb, comparándolos con los paradigmas de la época.

La geología de Talamanca, hasta donde la vio y entendió Gabb, le pareció muy "simple". Recordemos que también se refiere de esta manera a la geología de Santo Domingo, donde podemos constatar que Gabb observó plegamientos y 
discontinuidades geológicas, como se observa en sus perfiles geológicos (Gabb, 1873). Entonces el concepto de simpleza geológica debe haber tenido otra connotación para Gabb, y que ahora es difícil descifrar. Una de las posibilidades es que él considerara que la geología es simple desde el punto de vista que es relativamente joven, pues sólo empieza en el Mesozoico o Cenozoico, y no existen rocas más antiguas, siendo entonces demasiado joven para ser complicado y de hecho, esto significa que son terrenos geológicos que representan únicamente un 5\% de la totalidad de la edad de la Tierra. Hoy sabemos que la geología del lado caribe es sumamente complicada, pues conforma una faja plegada y sobrecorrida, que es parte del denominado Cinturón Deformado del Norte de Panamá, y que se extiende hasta Colombia. Pero justamente la complicación de la geología de esta región estriba en su carácter estructural, es decir: un fallamiento con planos de bajo ángulo, que causan una duplicación y repetición vertical de las capas sedimentarias, como ha sido demostrado en las perforaciones explotatorias de petróleo hechas en la segunda mitad del siglo XX. Parece ser entonces que justamente aquella deficiencia en el conocimiento del fallamiento geológico de nuevo hace que Gabb subestime su objeto de estudio en el Caribe. El punto es saber si era en realidad, una deficiencia en la educación de este científico, o en la época no eran de amplio conocimiento las fallas geológicas. Además recordemos que el desarrollo de las fajas sobrecorridas se dio fundamentalmente a partir del estudio de los Alpes, lo que representa ya una diferencia entre las escuelas estadounidense y europea.

Remitiéndonos a la historia de la geología, se habla de fallas por lo menos desde Lyell (1830-1833), quien define falla de la siguiente manera: "En el lenguaje de mineros, es la abrupta interrupción de la continuidad de un estrato en el mismo plano, acompañado por una fractura o fisura, con un ancho variable entre una mera línea a varios pies...", sin embargo, éstas no comienzan a ser entendidas justamente hasta el año 1889, cuando Le Conte, un geólogo estadounidense, establece la teoría de fallas, específicamente dice (tomado del resumen de Mather
\& Mason, 1970, p. 468): "La explicación de las fallas inversas parece suficientemente obvia. Ocurren, como hemos dicho, principalmente en regiones fuertemente plegadas. Estos pliegues sólo pueden ser producidos por presión lateral. Cuando la presión es extrema, produce replegamientos. Si tales repliegues se quiebran, la inclinación de la fisura será hacia la dirección desde la cual vino la presión y el techo [se refiere al bloque del lado superior de la falla] será empujado hacia adelante y hacia arriba sobre el piso [bloque inferior]... Pero la explicación de fallas normales, que son las más comunes no es tan obvia..."

Le Conte consideraba que la corteza terrestre flotaba en una subcorteza líquida y al producirse doblamientos de la corteza en forma de arco cóncavo hacia arriba, podía colapsarse a lo largo de fracturas que producían bloques prismáticos rectangulares, algunos de los cuales se hundían más que otros. Con esto, Le Conte explicaba lo que hoy se conoce como sistemas de fallas normales en "pilares y fosas". En Europa el geólogo francés Marcel A. Bertrand es el que ilustra las grandes fajas de sobrecorrimiento en los Alpes. Dibujó unos hermosos perfiles geológicos que ilustran de una manera sorprendentemente detallada estructuras plegadas y falladas (Mather \& Mason, 1970).

Con base en lo expuesto anteriormente, nos damos cuenta que aunque Gabb había trabajado en California, región con una deformación tectónica muy fuerte, probablemente nunca le prestó atención, justamente porque eran momentos en que el desarrollo de la geología estructural estaba apenas en sus inicios, y no es sino hasta una década después de su muerte, cuando se establecen las bases sobre las cuales se fundamenta el estudio de la geología estructural y tectónica.

En lo que respecta a la formación de montañas, Gabb ha debido estar muy consciente y muy al tanto de los últimos conocimientos de la época, ya que precisamente fue asistente de James Hall, uno de los dos precusores de la teoría de los Geosinclinales, "La teoría del Geosinclinal de Hall y Dana [expresada entre 1850 y 1860] sostenía que las mayores cordilleras del mundo se originaron en fajas de sedimentos, angostas 
pero de mucho espesor, que fueron depositados a lo largo de márgenes subsidentes de áreas continentales y subsecuentemente elevadas como cordilleras montañosas por la acción expansiva del calor a aquellos sedimentos que llegaron a exponerse [aflorar] luego de que ellos se hundieron en las partes profundas de la corteza de la tierra" (Adams, 1938, p. 397).

\section{COMENTARIO FINAL}

Consideramos, que aunque el mapa geológico que hizo Gabb de la región talamanqueña haya permanecido en el oscurantismo durante más de un siglo, es el primer gran legado geológico que nos deja uno de los científicos extranjeros que nos visitaron en el siglo XIX. Esto, sumado a sus publicaciones y sus escritos inéditos, constituyen una contribución a la geología de Costa Rica, a tal grado valiosa, que se debe reconocer en la figura de Gabb, al pionero de la geología en Costa Rica.

\section{AGRADECIMIENTOS}

A Rafael Oreamuno, quien nos facilitó una copia del mapa geológico de Talamanca de William Gabb. Michael Machette buscó y nos envió una copia de los manuscritos originales de la biblioteca del U.S. Geological Survey en Berkeley. Rudolf Fischer nos trajo una copia de la publicación de Petermann (1877), incluyendo el mapa geográfico de Gabb. Giovanni Peraldo nos ayudó enormemente con la consecusión de documentos en la Biblioteca Nacional. Guillermo Alvarado nos dio acceso a la colección de José Fidel Tristán depositada bajo su custodia en los Archivos Nacionales, donde encontramos numerosas referencias al trabajo de W. Gabb. Teresita Aguilar revisó la fauna denominada por Gabb. Gabriel Dengo nos dio información básica para localizar el mapa geológico inédito de la Talamanca. Esta publicación es una contribución del proyecto \# 113-97-249, titulado Historia de la Geología de Costa Rica, de la Vicerrectoría de Investigación de la Universidad de Costa Rica.

\section{REFERENCIAS}

ADAMS, F.D., 1938: The birth and development of the geological sciences.- 505 págs.; Dover Publ. Nueva York.

ADVOCATE, D.L. (seudónimo), 1998: The Paradigm: Thomas Kuhn and the Trojan Horse.- EOS, 79(5): 62.

AGUILAR, T., 1993: Paleoecología del Alto Guayacán, Formación Uscari, Mioceno, Limón, Costa Rica..- Rev. Geol. América Central, 16: 51-68.

ALVARADO, G.E., MORALES, L.D. \& SOTO, G.J., 1991: Historia del desarrollo de las Ciencias Geológicas en Costa Rica. - En: A.Ruiz (ed.): Ciencia y Tecnología. Estudios del pasado y del futuro. - Ed. Guayacán: 121-142, San José.

ANÓNIMO, 1997: Férreo Carril. - CARETAS: Ilustración Peruana 8/5/97, 1464: 44-48.

BELT, T., 1874: Glacial phenomena in Nicaragua. - American Jour. Sci. Arts. 3(7): 594-595.

CORONADO, G., 1997: La actividad científica en Costa Rica: un bosquejo de su evolución. - En: Zamora (ed.): El otro laberinto: 257-276; Ed. Tecnológica de Costa Rica, Cartago.

CORTÉS, J., FONSECA, A.C., BARRANTES, M. \& DENYER, P., 1998: Type, distribution, and origin of sediments of the Gandoca-Manzanillo National Wildlife Refuge, Limón, Costa Rica. - Rev. Biol. Trop. 46 (Supl. 6): 251-256.

DALL, W.H., 1909: Biographical Memoir of William More Gabb. - Natural Acad.Sciences, Biographical Mem. VI: 347-361.

DENGO, G., 1988: Historia del desarrollo del conocimiento geológico de América Central. 
- Anales de la Academia de Geografía e Historia de Guatemala. Año LXIV, Tomo LXII: 153-186.

DENYER, P. \& ARIAS, O., 1991: Estratigrafía de la región central de C.R. - Rev. Geol. América Central, 12: 1-59.

DRAPER, G. \& DENGO, G., 1990: History of geological investigation in the Caribbean region. - En: DENGO, G. \& CASE, J.E. (eds.): The Caribbean Region-Geology of North America: 1-14; Geol. Soc. America vol. H, Boulder-Colorado.

FERRERO, L., 1978: William M. Gabb y Talamanca. Presentación del libro Talamanca, el espacio y los hombres. - En Talamanca, el espacio y los hombres:VII-LXXIX; Ministerio de Cultura Juventud y Deportes, San José.

FUENTEALBA, N., 1977: El derecho minero de Costa Rica. - 169 págs.; Ed. Universidad de Costa Rica, San José.

GABB, W.M., 1873: On the topography and geology of Santo Domingo. - Trans. Am. Philos. Soc. 15: 49-259.

GABB, W.M., 1874: On the geology of the Republic of Costa Rica. - Manuscrito inédito en la biblioteca del U.S. Geol. Survey, 47 págs.

GABB, W.M.,1875: Notes on Costa Rica geology. - Am. J. Sci. 9: 198-204.

GABB, W.M., 1881a: Descriptions of Caribbean Miocene fossils. - J. Academ. Nat. Sciences of Philadelphia, 8: 337-348.

GABB, W.M., 1881b: Descriptions of new species of fossils from Pliocene Clay Beds between Limon and Moen, Costa Rica, together with notes on previously known species from there and elsewhere in the $\mathrm{Ca}$ ribbean area. - J. Academ. Nat. Sciences of Philadelphia, 8: 349-380 + 4 ilustraciones.
GABB, W.M., 1895: Informe sobre la exploración de Talamanca verificada durante los años 1873-1874 (Introducción de Henri Pittier). - 89 págs.; Tipografía Nacional, San José.

GEIKIE, A., 1962 [primera edición en 1897]: The founders of geology. - 486 págs.; Dover Publ., Nueva York.

GÓMEZ, L.D., 1977: Bibliografía geológica y paleontológica de Centroamérica y El Caribe. - 123 págs.; Museo Nacional de Costa Rica, San José..

GONZÁLEZ FLORES, L.F., 1976: Historia de la influencia extranjera en el desenvolvimiento educacional y científico de Costa Rica. - 296 págs.; Ed. Costa Rica, San José [El original fue publicado en 1921].

HOFFSTETTER, R., DENGO, G. \& WEYL, R., 1960: Introducción. Costa Rica. - En: HOFFSTETTER, R. (ed.): Lexique Stratigraphique International Amérique Centrale.- 5(2): 227-306 C.N.R.S., París.

I.C.R.M. (Instituto Cubano de Recursos Minerales, 1963: Diccionario minero-metalúrgicogeológico-Mineralógico-petrográfico y de petróleo. - 369 págs.; Inst. Cubano de Recursos Minerales, Buenos Aires-Argentina.

KUHN, T.S., 1971: La estructura de las revoluciones científicas. - 320 págs.; Fondo de Cultura Económica, México [6a. reimpresión de la 1a. edición española, 1985].

LEWIS, J.F. \& DRAPER, G., 1990: Geology and evolution of the northern Caribbean margin. - En: DENGO, G. \& CASE, J.E. (eds.): The Caribbean Region-Geology of North America:77-140; Geol. Soc. America vol. H, Boulder-Colorado.

LYELL, C., 1830-1833 (1991): Principles of geology vol. III. Chicago. - 398 págs. Univ. of Chicago Press [Facsímil de la primera edición]. 
MATHER, K.F. \& MASON, S.L., 1970 [primera edición en 1939]: A source book in geology. - 702 págs. Harvard University Press, Cambridge.

PETERMANN, A., 1920: El mapa topográfico de Talamanca de Mr. William M. Gabb y la cartografía de Costa Rica en 1877. Rev. de Costa Rica, 1(5): 153-157.

PETERMANN, A., 1877: Wm. Gabb's Aufnahme von Talamanca und der kartographische Standpunkt von Costa-Rica in 1877. Gotha 23: 385-387 + mapa.

PILSBRY, H.A., 1922: Revision of W.M. Gabb's Tertiary mollusca of Santo Domingo. Proc. Acad. Natural Sciences Philadelphia, 73: 305-435 + 45 figs.

RAMÍREZ, O., 1985: El carbón en Costa Rica. Rev.Geol. América Central, 2: 89-94.

SALAZAR NAVARRETE, J.M., 1996: La gran serpiente verde. - 367 págs.; EUNED, San José.

SCHUCHERT, C., 1935: Historical geology of the Antillean-Caribbean Region. - 311 págs.; John Wiley \& Sons, Nueva York.

SEEBACH, K. von, 1865a: Reise durch Guanacaste (Costa Rica) 1864 und 1865. - Petermann's Geogr. Mittelamerika, 9: 241-249.

SEEBACH, K. von, 1865b: Besteigung des Vulkans Turrialba in Costa Rica. - Petermann's Geogr. Mittelamerika, 9: 321-324.

SEEBACH, K. von, 1892: Über Vulkane Zentralamerikas. - 252 págs.; Dieterische Verlags-Buchlandlung, Göttingen.

STEWART, W., 1991: Keith y Costa Rica. [Traducción del inglés por José B. Acuña, 2a. Reimpresión, el original fue publicado en 1967]. - 240 págs.; Ed. Costa Rica, San José.
ULLOA, F., 1979: Historia minera en Costa Rica. - 50 págs.; Dir. de Geol., Minas y Petróleo, San José.

VILLALTA, C., 1986: La explotación de oro en Costa Rica. - Rev. Geol.América Central, 5: 109-113.

ZÚÑIGA, M., 1910(?): Reproducción artística del mapa de José Ma. Figueroa \& Oreamuno de 1883, escala aproximada 1:200 000 (Se encuentra en el Inst. Geogr. Nacional).

\section{APÉNDICE 1:}

\section{PUBLICACIONES ATRIBUIBLES A WILLIAM M. GABB}

\section{Trabajos geológicos originales sobre Costa Rica}

1874: Note on the geology of Costa Rica. Am.J. Sciences, 7:438-439.

1874: Note on the geology of Costa Rica. Am. J.Sciences, 8:388-390.

1874: On the geology of the Republic of Costa Rica. Manuscrito inédito en la biblioteca del U.S. Geol. Survey, 47 p.

1875: Notes on Costa Rica geology. Am. J. Sciences, serie 3, 9:198-204.

1881: Descriptions of new species of fossils from the Pleistocene clay beds between Limón and Moén, Costa Rica, together with notes on previously known species from there and elsewhere the Caribbean Area. Acad. Natural History of Philadelphia, 8:349-380.

\section{Otras publicaciones y reproducciones de sus informes sobre Costa Rica (con base en Gómez, 1977)}

1875: On the Indian tribes and languages of Costa Rica. Proc.Amer. Philosophical Soc. 14: 483-602.

1892: Exploración de Talamanca. 1873-1874. Anales Inst. Fis. Geogr. Costa Rica, 5:70-92. 
1893: Informe sobre la exploración de Talamanca verificada durante los años 1873-1874 (Introducción de Henri Pittier). San José: Tipografía Nacional, 89 p.

1895: Informe sobre la exploración de Talamanca verificada durante los años 1873-1874. Anales Inst. Fis. Nac. Costa Rica, 5(1892):67-90.

1895: Informe sobre la exploración de Talamanca verificada durante los años 1873-1874 (Introducción de Henri Pittier). San José: Tipografía Nacional, 89 pp.

1911: Esbozo general de la geología de Talamanca, Costa Rica. Bol. Fomento, 1:132136.

1913: Report of the Talamanca Exploration, made during 1873-1874 by W.M. Gabb. Costa Rica. Panama Arbitration, documents annexed to the argument of Costa Rica. U.S.A., 97-142.

1913: Exploración de Talamanca, 1873-1874. (Traducción española de la cita anterior). Anales Inst. Físico Geogr.de Costa Rica, 5:67-90.

1969 (traducción): Tribus y lenguas indígenas de Costa Rica. Rev. Archivo Nacional XXXIII:303-486.

1978: Talamanca, el espacio y los hombres (Introducción de Luis Ferrero). Ministerio de Cultura, Juventud y Deportes, pp.VII-LXXIX.

\section{APÉNDICE 2}

\section{CONTRIBUCIÓN A LA PALEONTOLOGÍA}

Nuevas especies existentes en Costa Rica denominadas por Gabb

Gasterópodos (30): Amusium lyonii GABB, Cerithium caribbeum GABB, Cerithium coyinsii GABB, Cerithium limonensis GABB, Cerithium lordlyi GABB, Cerithium moenensis GABB, Conus floridanus GABB, Dillia moenensis GABB,
Eulima crassilabris GABB, Lunatia emilunoides GABB, Lunatia sculturata GABB, Mangelia lata GABB, Mangelia subcilindrica GABB, Margarita tricarinata GABB, Metula cancellata GABB, Nassa caribea GABB, Natica milleri GABB, Oliva brevispira GABB, Olivella muticoides GABB, Parkeria inconspicua GABB, Parkeria vitrea GABB, Phos inornata GABB, Sigaretus multilineatus GABB, Terebra evansii GABB, Trochita collinsi GABB, Vitrinella crassicosta GABB, Vitrinella obliquestriata GABB, Vitrinella pentagona GABB, Vitrinella truncata $\mathrm{GABB}$, Volvula cylindrica GABB.

Bivalvos (17): Amusium lyonii GABB, Cerithium caribbeum GABB, Cerithium coyinsii GABB, Cerithium limonensis GABB, Cerithium lordlyi GABB, Cerithium moenensis GABB, Conus floridanus GABB, Dillia moenensis GABB, Eulima crassilabris GABB, Lunatia emilunoides GABB, Lunatia sculturata GABB, Mangelia lata GABB, Mangelia subcilindrica GABB, Margarita tricarinata GABB, Metula cancellata GABB, Nassa caribea GABB, Natica milleri GABB, Oliva brevispira GABB, Olivella muticoides GABB, Parkeria inconspicua GABB, Parkeria vitrea GABB, Phos inornata GABB, Sigaretus multilineatus GABB, Terebra evansii GABB, Trochita collinsi GABB, Vitrinella crassicosta GABB, Vitrinella obliquestriata GABB, Vitrinella pentagona GABB, Vitrinella truncata $\mathrm{GABB}$, Volvula cylindrica GABB.

Escafópodos (2): Caecum anulatun GABB, Caecum crassicostum GABB.

Equinoideo (1): Schisaster scherzeri GABB

Especies nuevas denominadas en honor a Gabb

Sconnia laevigota vol. gabbi OLSSON, Sigaretus (eunnaticina) gabbi BROWN \& BRY, Typhus gabbi BROWN \& BRY. 